\title{
The Prudential Value of Forgiveness
}

\section{Stephen Ingram}

\begin{abstract}
Most philosophers who discuss the value of forgiveness concentrate on its moral value. This paper focuses on the prudential value of forgiveness, which has been surprisingly neglected by moral philosophers. I suggest that this may be because part of the concept of forgiveness involves the forgiver being motivated by moral rather than prudential considerations. But this does not justify neglecting the prudential value of forgiveness, which is important even though forgivers should not be prudentially motivated. Forgiveness helps satisfy interests arising from the need for co-operation in such areas as epistemic life, where humans are interdependent. Forgiveness can restore epistemic relationships, and this has the prudential value of helping agents navigate their way through their environment. While the prudential value of forgiveness may be supplementary to its moral value, it would be a mistake to ignore this area of the debate. Exploring the prudential value of forgiveness enriches our understanding of the role that this practice plays in human life, and may contribute to explaining the origin of forgiveness.
\end{abstract}


Forgiveness is a practice that we value. Most discussions of the value of forgiveness focus on how this practice is morally valuable. This is an interesting and important issue, but in this paper I am more interested in discussing the prudential value of forgiveness. How does the practice of forgiveness contribute to the satisfaction of the needs, desires, and interests of individuals and communities? This important aspect of the philosophical debate on forgiveness has been surprisingly neglected. Indeed, an article published recently in this journal (Kaspar 2011) indicates that suspicion or neglect of the role that prudence plays in ethics is a common feature of contemporary moral philosophy. According to Kaspar, the mainstream view among philosophers who discuss morality and prudence is that these things are opposed, with each being confined to an exclusive sphere of reason (ibid., 313n.5).

The aim of this paper is to show that moral philosophers should pay more attention to the prudential value of forgiveness. In $\S 1$ I explore why they have neglected this area, arguing that any grounds for this neglect are superficial. In §2 I argue that one way in which forgiveness is prudentially valuable lies in its helping to meet a need for co-operation in those areas of life in which humans are interdependent. I concentrate on epistemic interdependence, showing how the practice of forgiveness contributes to maintaining and promoting the pool of information that individuals rely on to steer their way through their environment successfully. Finally, in $\S 3$ I suggest that the failure to attend to the prudential value of forgiveness has obscured important aspects of the role this practice actually plays in our lives. I will conclude that it would certainly be a mistake to continue the neglect of the prudential value of forgiveness.

\section{1}

Let us say that a prudent act is one that will generally help make one's life go better. Prudent acts contribute to the satisfaction of one's needs, desires, interests, and so on. So, to claim that forgiveness is prudentially valuable is to claim that forgiving, and being disposed to forgive, tends to contribute to one's wellbeing. In the current debate, the prudential value of forgiveness is frequently ignored, overlooked, or dismissed. Of course, most moral philosophers would accept that forgiveness frequently has prudential value. Their neglect of the prudential value of forgiveness is not due to the thought it does not make life go better. It is more likely due to the thought that this is not an important or an interesting fact about 
forgiveness. In my view, it is a mistake to neglect or dismiss the importance of the prudential value of forgiveness.

It is worth recognising from the outset that some moral philosophers have considered the prudential value of forgiveness to be important and worth discussing in depth. For instance, Geoffrey Scarre takes a utilitarian view of the value of forgiveness, arguing that this practice "is at its most valuable when it reunites people in mutually beneficial relationships" $(2004,25)$. When one party injures another, this disrupts their relationship. The relationship may be restored through the process of forgiveness. Most would agree that reconciliation is normally a valuable result of forgiving. ${ }^{1}$ But by pointing to the importance of the mutual benefits provided by these relationships Scarre acknowledges the significance of the prudential value of forgiveness, which he sees as inextricable from its moral value. Scarre's emphasis on the prudential benefits of forgiveness is unusual. More commonly, the value of restoring some abstract sort of moral relationship is the focus of moral philosophers. We will return to this point in $\S 2$, but for now the important idea is that the prudential value of restoring a relationship is typically taken to be a pleasant but uninteresting side-effect of forgiveness, and is thus given little or no attention by most ethicists.

Even when the prudential value of forgiveness is discussed by moral philosophers, its role in our understanding of forgiveness is often downplayed. For instance, Charles Griswold mentions that one might decide to relinquish resentment for reasons of "psychological or social survival" $(2007,111)$, but stresses that forgiveness is not necessarily connected to such self-preserving aims. And Jeffrie Murphy acknowledges the suggestion that forgiving can provide benefits to one's physical health. When one is wronged one naturally has negative feelings towards the wrongdoer. By forgiving, one relinquishes these negative feelings and thereby promotes one's health and general wellbeing. Empirical research indicates that maintaining such feelings can be damaging to us psychologically as well as physically. ${ }^{2}$ The health benefits

\footnotetext{
${ }^{1}$ As I will note in $\S 2$, reconciliation is not always a valuable outcome of forgiveness. For instance, there may be cases in which it is admirable for a woman to forgive her abusive ex-partner, but full reconciliation would not be desirable in such circumstances.

2 Traits of anger, for example, are a risk factor for coronary heart disease. For an important exploration of the therapeutic value of forgiveness, see Enright, Gassin and Wu (1992). See also the volume edited by Murphy and Lamb (2002).
} 
of forgiveness are one of the ways in which it seems to be prudentially valuable; forgiveness benefits the offended party by getting rid of the festering bitterness and anger that she is carrying around. However, Murphy seems to regard this as philosophically uninteresting (2003, viii).

Eve Garrard and David McNaughton are very critical of the idea that the primary value of forgiveness might lie in its therapeutic or health benefits. They rightly say that "we characteristically think of forgiveness, and forgivers, as being generous, and that is hard to understand if we think of forgiveness as primarily benefitting the forgiver" $(2010,13)$. In other words, forgiveness is often seen as a gift that the victim gives to the wrongdoer if she so chooses. But if the victim is attending to what's in it for her - that is, if she is responding the prudential value of forgiving then it is hard to think of what she does as really being forgiveness. On this view, seeing forgiveness merely as a means to some positive outcome for the forgiver fails to get to the heart of what forgiveness is about. This is one factor that may lead to the prudential value of forgiveness being ignored or dismissed as unimportant for our understanding of forgiveness.

Another factor, not unrelated, stems from the standard understanding of the concept of forgiveness. Forgiveness is commonly conceptualised as the letting go of resentment for moral reasons (see, for example, Griswold 2007, 40). More precisely, forgiveness is taken to be a way of responding to wrongdoing that involves the relinquishing of resentment (and/or connected negative feelings, such as anger and hatred) that a wronged individual holds towards the person who wronged them. ${ }^{3}$ For this relinquishing of negative feelings to be forgiving rather than some alternative response to wrongdoing (such as excusing or condoning), the wronged party must be responding to pertinent moral considerations. For example, if the wrongdoer repents and seeks to change her ways, this provides the victim with moral grounds for forgiving. Given that the moral motivations of the forgiver seem to be part of the concept of forgiveness, it might seem that an agent who is motivated by the prudential value of relinquishing her negative feelings is just not forgiving. And that might be another ground for ignoring the

\footnotetext{
3 Glen Pettigrove (2012, 2-9) suggests that forgiveness can occur even when no resentment is present. He argues it is a broader class of hostile reactive attitudes and feelings that is relevant to forgiveness, and I am sympathetic to this. However, for brevity, I will tend to talk about resentment or negative feelings that are relinquished by the forgiver, rather than the broader group of attitudes suggested by Pettigrove.
} 
prudential value of forgiveness; this sort of value just is not anything to do with the nature of forgiveness. Being prudentially motivated is simply not part of what it is to forgive.

What connects these two grounds for side-lining the prudential value of forgiveness is a view about how what is going on with the agent who forgives is linked to the concept of forgiveness. The importance of the prudential value of forgiveness is rejected because part of the concept of forgiveness involves the forgiving agent being generous, and being motivated by her appreciation of the intrinsic moral value of forgiving. These are not properly accounted for if the focus is on how forgiveness is prudentially valuable; if the agent is responding to considerations about how relinquishing her negative feelings will benefit her then her actual relinquishing of those feelings just will not constitute forgiveness.

I am happy to accept this. Indeed, I think that it would be quite wrong to reject it. That genuine forgiveness involves the forgiver responding to moral considerations is part of what it is to forgive. My contention is simply that this claim does not provide a satisfactory ground for neglecting or rejecting the prudential value of forgiveness. Taking the prudential value of forgiveness seriously does not require that we interfere with or alter our standard concept of forgiveness. We do not have to maintain that the forgiver should be focused on what's in it for her, and we can agree that she would not be forgiving if she was making a self-interested bargain of some kind when deciding to relinquish her resentment. That is, we can and should accept that the agent is not really forgiving the wrongdoer if her decision to let go of her negative feelings is responsive to prudential rather than moral value.

Instead, we can focus on the broader benefits that forgiveness provides to communities as well as to the individuals living within communities. Taking the prudential value of forgiveness seriously does not require that we ignore its moral value, or that we challenge the role that this moral value plays in the agent's deliberation over whether or not to forgive. It is worth our attention regardless of the fact that, on its own, it is not essential to the contemporary concept of forgiveness. The prudential value of forgiveness could still play an interesting and significant role in our lives, but we cannot satisfactorily understand this role unless we give the prudential value a proper investigation. This is why I think the neglect or dismissal of this area has been a failure among moral philosophers who talk about forgiveness. 
As I acknowledged above, one way in which forgiveness has a prudential value relates to the benefits it provides to health and wellbeing. However, this is not what I will be discussing here. It is beyond the scope of this paper to discuss all of the ways in which forgiveness may be prudentially valuable. I will focus on one way that I think may be fruitful, and deserves more attention. By highlighting a philosophically interesting way in which forgiveness can be prudentially valuable, I hope to make it plausible to think that we should spend more time talking about the prudential value of forgiveness. If we ignore the prudential roles that forgiveness plays in our lives, our understanding of forgiveness will be impoverished.

On the account that I want to present, it is an interesting and important fact about forgiveness that it is prudentially valuable in those areas in which humans are interdependent. This is what I will consider next, with specific reference to epistemic interdependence.

\section{2}

It is well-known that human beings are epistemically interdependent. Our knowledge and our capacity to acquire knowledge would be seriously restricted if we sought to be entirely independent in our epistemic activities. In day-to-day life and in our more rigorous intellectual practices, we benefit from the inquiry, the knowledge and the justified beliefs of others. You tell me about the two-for-one deal on washing powder at the supermarket, and I use this information to save some money. My academic inquiry is pushed further by the insightful comments you give on my paper, and this makes my views more refined. The testimony of others assists in our efforts to successfully steer our way through whatever sphere of activity we are engaged in. In short, we have epistemic relationships with those with whom we interact, and these relationships are prudentially valuable. They make our lives go better.

Some philosophers - Edward Craig (1990), Bernard Williams (2002), and Miranda Fricker (2007) - have articulated and developed this point by highlighting how the need to believe truths would play a significant role in the lives of the inhabitants of a hypothetical state of nature, a concept borrowed from the social contract tradition of political philosophy. Making use of the state of nature involves examining how certain concepts or values or institutions would have originated and developed in a minimal human environment that lacked those concepts or values or institutions. The idea is that we can learn something about 
the needs and interests that such things are responsive to by asking how they would have come about in a simplified situation. Many political thinkers have asked how the state and its binding political institutions would have originated and developed in the state of nature. And recently, it has been suggested that the state of nature can be useful for understanding our epistemic concepts and values.

For instance, Craig uses a state of nature scenario to gain insight into the concept of knowledge. He observes that individuals need sources of information that will help them believe truths $(1990,11)$. The concept of knowledge is used to flag approved sources of information, and these sources of information will often be other people. Williams uses the state of nature to tell a genealogical story about the value of truth and truthfulness. He points out that the inhabitants of the state of nature need to pool information, and that this has the significant implication that there will be a division of epistemic labour $(2002,43)$. And Fricker argues that we can trace the genealogy of the virtue of testimonial justice by making use of the state of nature. This virtue helps to sustain trust as regards acquiring knowledge from the pool of information that individuals rely on to steer their way through life in the state of nature $(2007,116)$. These are all considerations that indicate and articulate the epistemic interdependence of human beings.

The idea of interest here is that human beings - whether or not they are in the state of nature - have a need for a pool of reliable information. It is in their interests for there to be such a pool so that they can draw on it in order to navigate their way through their environment. This brings with it an interest in having most people be reliable informants; it benefits the community if most people are disposed to transmit true beliefs to the pool of information. Those character traits that lead to a stable epistemic community are prudentially valuable insofar as they contribute to the maintenance of the pool of reliable information. Truthfulness is crucial here, according to Williams, and its fundamental virtues are Accuracy and Sincerity (he capitalises them in order to acknowledge that, given his genealogical state of nature methodology, they are abstractions). Fricker adds a third fundamental virtue of Testimonial Justice (capitalised for the same reason). By emphasising that these traits are fundamental virtues of the inhabitants of a stable epistemic community, Williams and Fricker suggest that they are traits that are not just prudentially valuable. They also get to be intrinsically valuable because their role in human life is so basic. They are 
virtues that must arise in human society, and this makes them intrinsically valuable for human beings.

I want to suggest that forgiveness also has a prudential value insofar as it contributes the maintenance of a stable epistemic community and a reliable pool of information. I do not, however, commit to the strong claim that the disposition to forgive is a fundamental virtue in the sense suggested above: it seems possible that there could be a sustainable epistemic community without the widespread practice of forgiveness, and I do not wish to claim here that the intrinsic moral value of forgiveness derives from its prudential role in epistemic life. But even if the intrinsic moral value of the practice of forgiveness comes from somewhere other than its prudential value, this does not mean that we should overlook the way in which forgiving benefits the epistemic interests of individuals and communities. Similarly, I could live without the benefits of doing philosophy, but it is still an important fact about me that doing philosophy contributes to my wellbeing. So, how does forgiveness contribute to our epistemic needs? How does it help to sustain a stable epistemic community with a pool of reliable information?

The first thing to note is that, as I mentioned above, most individuals have a range of prudentially valuable personal epistemic relationships with the people with whom they regularly come into contact. We trade knowledge and beliefs to inform and co-ordinate our conduct. This is a co-operative activity that enables us to make better decisions based on how reliable we take the given information to be. This is one of the ways in which human beings are epistemically interdependent.

Now, errors and deceit are inevitable feature of both moral and epistemic life. Suppose that two individuals have a successful epistemic relationship but that one in some way wrongs the other. The restoration of this epistemic relationship would be prudentially valuable to both parties. Establishing that another individual is a reliable informant presumably takes some time and effort, so in many cases it would be in the interests of both parties to become reconciled through forgiveness. This enables the joint and individual enquiries of these epistemic agents to continue and progress. Again, this does not mean that the prudential value of restoring the epistemic relationship is what ought to motivate the wrongdoer and the wronged in their respective efforts to be worthy of forgiven and to forgive. But it is still the case that becoming reconciled 
through forgiveness would be prudentially valuable for these agents. It would benefit them to restore their relationship.

Restoring an epistemic relationship is partly a process of restoring trust in that relationship. But we should emphasise that forgiveness is not the same thing as the restoration of trust. Forgiveness merely tends to lead to restored trust, and most ideal cases of forgiveness will involve the restoration of a trusting relationship. But it is certainly not always desirable for the forgiver to trust the person who wronged them. The standard example is that of a woman who was abused by her ex-partner. It might be admirable for the woman to forgive the abuser (though, of course, we should not expect her to do so) but we would rarely think it sensible for her to trust him again. The fact that it can be desirable to forgive without restoring trust indicates that the restoration of trust is not a necessary condition for forgiveness to have occurred.

However, I do not need to claim that forgiveness always makes a prudentially valuable contribution to the restoration of an epistemic relationship through the restoration of trust. I merely have to suppose that this happens often enough for it to be an interesting fact about forgiveness, and it seems quite plausible that this is indeed the case. This allows us to identify one way in which forgiveness contributes to having a stable epistemic community: it helps with the restoration of trusting epistemic relationships between individuals who regularly come into contact.

But we also think that forgiveness can occur between people do not know each other. If you carelessly crash into my car, I am able to forgive you even though there was no substantial relationship between us prior to our vehicular collision. Initially it looks as though there is simply no relationship to be restored here, and that might seem to exclude the possibility of forgiveness between people unfamiliar with each other. However, many philosophers argue that the relationship that is restored in such cases is a moral relationship. The notion of a moral relationship might seem mysterious, but Robert C. Roberts notes that many "moral outlooks make it quite explicit what that relationship is: members of a kingdom of ends, brother and sisters, children of God, fellow sojourners upon this earth" and so on (Roberts 1995, 294). When one is injured by someone with whom one is unfamiliar it is this sort of relationship that gets disrupted and that can be restored by forgiveness.

One might object that the mere sharing of a moral status - such as membership of a kingdom of ends or fellow earth-sojourning - only 
counts a relationship in a very broad sense, and that this sense is too broad for it to do the work required by an account of forgiveness. However, I am happy to grant that forgiveness can involve the restoration of a moral relationship. After all, 'relationship' is merely a catch-all term for a variety of ways that individuals can be connected. There can be loving relationships, caring relationships, business relationships and people on opposite sides of the world may, through some complex sequence of events, be involved in a causal relationship. Given that forgiveness is possible between people who do not know each other, can we say anything about how such forgiveness is prudentially valuable? What contribution does it make to epistemic life, in which we are interdependent?

It makes the same contribution as that between people who do know each other, but in an indirect way. In addition to having an abstract moral relationship, people who do not know each other are also epistemically related. But this epistemic relationship is not a personal one. To see how people who do not know each other are epistemically related, consider that epistemic agents generally benefit from keeping their channels of communication open. Being ready and willing to participate in the exchange of information with those who have something to offer in return is advantageous to us. We would lose out on valuable information if we were constantly suspicious of what unfamiliar people said.

This connects to one of the points that Williams makes about the value of truthfulness in the state of nature. Truthfulness contributes to the community's "interest in having correct information about the environment, its risks and opportunities" (2002, 58). Admittedly, as Williams points out, it is not automatically obvious that being truthful is always valuable for the individual. Individuals may benefit from 'freeriding' on the truthfulness of others. That is, they may gain from other individuals' information while keeping their own information to themselves. Thus, the collective value of Sincerity (one of Williams' fundamental virtues of truth) may not translate itself into a reason that each individual has for being sincere themselves (ibid.).

However, this problem can be defused somewhat by referring to the personal epistemic relationships that will be important to almost every individual in the state of nature. The inhabitants of the state of nature will make decisions based on their judgements about the reliability of the information provided to them by those with whom they 
have personal epistemic relationships. They therefore have to be able to trust those people. Successful epistemic relationships will be those where the participants do not feel as though the other is withholding information at their expense. So we may be justified in supposing that individuals have a good reason to have a general disposition towards truthfulness because this will help them to sustain epistemic relationships based on mutual trust.

The fact that being truthful and open to exchanging information with others is advantageous in this way opens the door to saying that people who have not met before have epistemic relationships that can be restored, and that are worth restoring. Roughly put, we can imagine that the pool of information is established through the exchange of knowledge and beliefs among individuals spreading across a population. As Williams says, "various observers are in different situations, and they then transport to the pool beliefs (in the favourable case, true beliefs or, again, knowledge) which each of them has acquired from being in that situation" (ibid, 43-44). Each epistemic agent relies to some extent on the pool of information and therefore to all those who contribute to it, whether or not they come into direct contact with them. This is another example of interdependence in epistemic life; there is a kind of web of belieftransmission that has the prudentially valuable result of assisting our navigation of the environments in which we find ourselves.

In other words, the epistemic agents of a community are all epistemically related: assuming that everyone will make some contribution to the pool of information, we may say that there are channels of communication linking each individual agent with every other individual agent. When one person wrongs another, this breaks down a communicative channel and harms the epistemic interests of the individual and the community. Being disposed to restore that communicative channel (by forgiving or putting in whatever efforts are required to be forgiven) would thus be prudentially valuable because it would maintain and promote the pool of reliable information. This in turn would aid individuals in successfully navigating the risks and opportunities of their environment.

Here, then, is how forgiveness is prudentially valuable in epistemic life. Even among individuals who do not know each other, there are epistemic relationships that can be restored through forgiveness. One of the ways in which forgiveness is prudentially valuable, then, is to do with our epistemic interdependence. While the prudential value of 
forgiveness should not be what motivates the forgiver to forgive, or the wrongdoer to seek to be worthy of forgiveness, it is a fact about the practice of forgiveness that it has this prudential value. In the next section I will explore why I think that this fact is interesting and important.

\section{3}

Someone dismissive of the importance of the prudential value of forgiveness might agree with what we have said, and yet regard it as uninteresting. Given that we need not think of the argument made above as interfering with the contemporary concept of forgiveness (which, as we saw, requires the forgiver to be motivated by moral considerations), one might wonder why the prudential value of forgiveness matters. What is the point in paying attention to it, if it does not tell us anything new about the nature of forgiveness? I suggest that it helps us to understand the role forgiveness actually plays in our lives, that it may help us to better understand those areas of life in which we are interdependent, and that it might contribute to an explanation of the origin of the practice of forgiveness.

One reason to think that the prudential value of forgiveness is worth philosophical attention is simply that it has so often been neglected, and the role that it actually does play in our lives is therefore underdeveloped. I do not think that this should be downplayed, as having an improved understanding of the prudential value of forgiveness can only enrich our view of the role that this practice plays in human activity. Even though the prudential value of forgiveness is supplementary to its moral value when we think about what it is to forgive, identifying the ways in which forgiveness is prudentially valuable fills in the details of how this practice actually functions in our lives. This is especially true if we can extrapolate something more general from the argument made in $\S 2$. There I focused on epistemic interdependence, but it is plausible that the argument generalises to the various other forms of interdependence that obtain in human communities. If forgiveness has a general role to play in co-ordinating the activities which require conscious or subconscious co-operation, surely that is an important fact about it. Moreover, it will also be an important fact about those practices. For instance, considering the prudential value of forgiveness by placing it in the context of the fact of human epistemic interdependence may shed new light on the social aspects of our epistemic lives. 
Another reason to pay attention to the prudential value of forgiveness lies in the possibility that this might contribute to a plausible explanation of the origin of forgiveness. It is beyond the scope of this paper to delve into considerations about the evolutionary, sociological and anthropological origins of moral practices, but it is not implausible to think of the modern practice of forgiveness as having emerged from a more basic practice of relinquishing resentment for prudential or instrumental reasons. Contemporary research on early notions of forgiveness highlights the historical presence of such non-moral versions of 'forgiveness'. For instance, Anthony Bash (forthcoming, n.5) observes that, in the Jewish tradition's early rabbinic period, 'forgiveness' functioned as an instrument of legal administration. It limited the retributive rights of a victim once the penalty had been paid by the wrongdoer. Such instrumental roles may have helped established stable practices of relinquishing resentment, and it is quite conceivable that our moral understanding of forgiveness is a spin-off from that kind of instrumentally valuable practice. ${ }^{4}$

I would suggest that, if we were to undertake a detailed examination of the way that forgiveness might have originated and developed in the state of nature, we should not be surprised to find that the prudential value of relinquishing resentment can plausibly be seen as having played a key factor in the origin of our contemporary practice of forgiveness. Having such a practice helps with co-operation and coordination, and re-forges bonds between people separated by wrongdoing. Having forgiving dispositions would be advantageous for individuals in the state of nature, or in the environment of our evolutionary ancestors. I have doubts over whether we should make the strong claim that forgiveness is a fundamental virtue - a virtue that must arise in human society. But it seems plausible to at least make the following weaker claim: forgiveness (or something near enough) is likely to emerge in most human societies as a response to the need for cooperation in such areas as epistemic life, where individuals are interdependent. This is because forgiveness tends to promote the restoration of trusting relationships, which are prudentially valuable in human communities. This weaker claim is enough to suggest this form of

${ }^{4}$ For discussions of early notions of forgiveness, see the volume edited by Griswold and Konstan (2012). 
prudential value may make an interesting contribution to philosophical work on the origin of forgiveness.

It thus seems possible that there is a discernible path by which morally isolated individuals in a state of nature environment can arrive at a state in which they share a moralized practice of forgiveness, where this outcome is achieved by way of an intermediate state in which, for prudential reasons, individuals relinquish resentment about injuries done to them. This is only speculation, and we would need a more detailed argument to agree that the prudential value of forgiveness played a significant role in originating that practice. But my point is merely that this is worth exploring, and philosophers risk missing something interesting and important if they neglect the prudential value of forgiveness. Our image of the place of forgiveness in human communities will be improved if we attend to its prudential value.

So, forgiveness has a prudential value and we should take this value seriously. It does not undermine the moral value of forgiveness to pay attention to how it benefits the individuals and the communities who engage in this practice. Rather, it can enrich our understanding of forgiveness and human interdependence, and opens up new lines of inquiry into the origins of the practice of forgiveness. I have focused on the prudential value of restoring epistemic relationships even among individuals not known to each other before the wrongdoing. Its role in our epistemic lives, then, is one of the ways in which forgiveness is prudentially valuable. There may be many others, and it would thus be a mistake to continue to neglect the prudential value of forgiveness.

\section{Acknowledgements}

For helpful comments on drafts of this paper, I am grateful to Geoffrey Scarre and Ian James Kidd. I would also like to thank Aaron Wilson, Holly Havens, Lizzy Kirkham, and audiences at the University of Durham and the University of Leeds. 


\section{References}

Bash, A. (Forthcoming). Did Jesus Discover Forgiveness? Journal of Religious Ethics.

Craig, E. (1990). Knowledge and the State of Nature: An Essay in Conceptual Synthesis. New York: Oxford University Press.

Enright, R.D., Gassin, E.A. \& Wu, C-R. (1992). Forgiveness: A Developmental View. Journal of Moral Education 21, 99-114.

Fricker, M. (2007). Epistemic Injustice: Power and the Ethics of Knowing. Oxford: Oxford University Press.

Garrard E., \& McNaughton, D. (2010). Forgiveness. Durham: Acumen.

Griswold C.L. (2007). Forgiveness: A Philosophical Exploration. New York: Cambridge University Press.

Griswold, C.L. \& Konstan, D (eds). 2012. Ancient Forgiveness: Classical, Judaic, and Christian. New York: Cambridge University Press.

Kaspar, D. (2011). Can Morality Do Without Prudence? Philosophia 29, 311-326.

Murphy, J.G. \& Lamb, S (eds). (2002). Before Forgiving: Cautionary Views of Forgiveness in Psychotheraphy. New York: Oxford University Press.

Murphy, J.G. (2003). Getting Even: Forgiveness and Its Limits. New York: Oxford University Press.

Pettigrove, G. (2012). Forgiveness and Love. Oxford: Oxford University Press.

Roberts, R.C. (1995). Forgivingness. American Philosophical Quarterly 32, 289-306.

Scarre, G. (2004). After Evil: Responding to Wrongdoing. Aldershot: Ashgate Publishing Limited.

Williams, B. (2002). Truth and Truthfulness: An Essay in Genealogy. Princeton: Princeton University Press. 